\title{
Rapid Oxidation of Skin Oil by Ozone
}

\author{
Shouming Zhou, Matthew W. Forbes, Yasmine Katrib, Jonathan \\ P.D. Abbatt
}

\author{
Version Post-print/Accepted Manuscript \\ Citation Zhou, S., Forbes, M.W., Katrib, Y., Abbatt, J.P.D., 2016. Rapid \\ (published version) Oxidation of Skin Oil by Ozone. Environ. Sci. Technol. Lett. 3, 170- \\ 174. https://doi.org/10.1021/acs.estlett.6b00086. \\ Copyright / License This document is the Accepted Manuscript version of a Published \\ Work that appeared in final form in Environmental Science \& \\ Technology Letters, copyright (C) American Chemical Society after peer \\ review and technical editing by the publisher. To access the final edited \\ and published work see \\ https://pubs.acs.org/doi/10.1021/acs.estlett.6b00086.
}

How to cite TSpace items

\begin{abstract}
Always cite the published version, so the author(s) will receive recognition through services that track citation counts, e.g. Scopus. If you need to cite the page number of the author manuscript from TSpace because you cannot access the published version, then cite the TSpace version in addition to the published version using the permanent URI (handle) found on the record page.
\end{abstract}

This article was made openly accessible by $U$ of $T$ Faculty. Please tell us how this access benefits you. Your story matters. 


\title{
Rapid Oxidation of Skin Oil by Ozone
}

\author{
Shouming Zhou*, Matthew W. Forbes, Yasmine Katrib, Jonathan P.D. Abbatt \\ Department of Chemistry, University of Toronto \\ 80 St. George St. \\ Toronto, ON, M5S 3H6, Canada
} \\ * - to whom correspondence should be addressed (Tel. +1-416-946-7359; Fax. +1-416-946- \\ 7359; email: szhou@chem.utoronto.ca)
}

\section{4}




\section{Introduction}

40 A major advance in our understanding of the chemistry of the indoor environment is recognition

41 of the role of human occupants. ${ }^{1}$ One class of impacts arises from multi-phase chemistry, 42 especially skin oils present either on human subjects or flakes/oils deposited in indoor 43 environments. ${ }^{2-4}$ Gas-phase products arising from the ozonolysis of carbon-carbon double bonds 44 within skin lipids have been identified. ${ }^{3-6}$ As well, the rate of ozone deposition in indoor 45 environments and ensuing chemistry depends on the level of human occupancy, where reactive 46 loss of ozone can occur directly either on humans, their soiled clothes or skin materials that they 47 deposit. $^{4,6-12}$

49 The multi-phase reactions of ozone with condensed-phase unsaturated organics occur 50 efficiently. ${ }^{13,14}$ Typical functional groups formed from ozone reacting with an alkene include 51 carbonyls, carboxyls, hydroxyl ketones and potentially hydroxyhydroperoxides. To better 52 understand the nature of chemistry occurring indoors arising from skin oil chemistry, experiments 53 have examined the oxidation of squalene with ozone. ${ }^{15-19}$ The kinetics are fast, with reactive uptake 54 coefficients of $10^{-5}$ to $10^{-3}$. Both gas- and condensed-phase products have been identified, 55 including carbonyls, acids, peroxides and ethers. ${ }^{16,17,19}$ The condensed-phase products are more 56 hydrophilic and redox-active than squalene. ${ }^{18}$ As well, the oxidation products of fabrics soiled with 57 squalene have been studied under ambient conditions. ${ }^{20}$

Many studies have been conducted on the chemical composition of skin surface lipids, with major components including long-chain alkenes (e.g. squalene, $10 \%$ by mass), saturated and unsaturated triglycerides (25\%), fatty acid esters (22\%), long-chain saturated and unsaturated fatty acids $(25 \%)$, sterols $(2 \%)$ and natural moisturizing agents (a few percent). ${ }^{21-26} \mathrm{We}$ do not attempt to

63 reproduce these compositional studies. Rather, our goals in this work are to use DART-MS ${ }^{27}$ to: i) 64 analyze the change in the composition of skin oil upon exposure to ozone, identifying the species that react most efficiently and the oxidation products that remain in the condensed phase, and ii) assess the oxidative transformation timescales of key components at an environmentally relevant

67 ozone mixing ratio. The motivations are to: i) provide kinetic information to interpret rates of ozone loss in inhabited indoor spaces, ii) identify components of skin oil that are unreactive with 
ozone that could be used to track human input to surfaces, and iii) identify condensed-phase

70 oxidation products to understand the factors impacting the composition of indoor surfaces.

71 Condensed-phase products have not been previously identified upon exposure of skin oil to ozone,

72 even though this chemistry will be occurring in both indoor and outdoor environments.

\section{Experimental}

75 Experiments were conducted using DART-MS analysis. ${ }^{28}$ Samples are deposited onto the lower 5 $76 \mathrm{~mm}$ of $1.6 \mathrm{~mm}$-o.d. glass capillaries mounted in a Teflon holder. For skin oil, participants 77 reproducibly touched the tip of the capillary with their fingers. Prior to applying the skin oil, the participants had not used personal care products for two days. They washed their hands with soap and water, and then rubbed hands over face and arms. Although we present the oxidation mass spectra of one specific male participant's skin oil, we also examined the spectra of three other male participants. The major spectral features were observed in all four skin oil samples although, as expected, there were variations in relative intensities of peaks from participant to participant, and from day-to-day; however, this variability is not relevant to the kinetics results. Rather it is the variability of the measurements amongst a set of coated tubes (commonly $\pm 20 \%$ for 10 replicates) that impacts the precision of the kinetics. The pure substances used as references in the product analysis (100 ng) were applied as $1 \mu \mathrm{L}$ dilute solutions in dichloromethane to the tip of the glass capillary, after which the solvent evaporated. The relative standard deviation of major peaks was also $\pm 20 \%$. We believe that this analytical method is largely sensitive to the free molecules present in the sebum (i.e. fatty secretions from the sebaceous glands) rather than lipid materials that are physically bound in the epidermis.

92 Ozone exposure was conducted at $295 \pm 3 \mathrm{~K}$ by placing the mounted capillaries in a glass flow tube

93 through which ozone mixed in air flowed with a residence time of $\sim 40 \mathrm{~s}^{28}{ }^{28}$ We performed control

94 experiments whereby both pure component and skin oil samples were analyzed for time periods

95 up to 90 minutes with no ozone, and we observed no loss of signal due to volatilization beyond 96 the variability stated above. After ozone/air exposure the samples were stored in a desiccator where 97 a small flow of nitrogen was added to avoid contamination from room air. 
DART-MS analysis was performed by passing the coated capillaries in front of the ion source

100 (IonSense Inc.) on a motorized rail at a speed of $0.3 \mathrm{~mm} / \mathrm{second}$. The DART source was held at

$101500^{\circ} \mathrm{C}$, resulting in $(280 \pm 20)^{\circ} \mathrm{C}$ at the capillary sample, and used a helium flow of 3.0 liter/min.

102 Ambient air from the lab was present in the source region. Mass spectra were measured with a

103 JMS-T100LC time-of-flight mass spectrometer (JEOL USA Inc.) having mass resolution of

104 approximately 6000 at a mass-to-charge ratio $(\mathrm{m} / \mathrm{z}) 600$.

105

106 Results and Discussion

107 1. Skin oil characterization

108 A typical positive ion mass spectrum of skin oil is shown as the red trace in Figure 1a which has 109 four noteworthy features. First, two of the strongest peaks are due to squalene (Molecular Weight, $110 \mathrm{MW}=410.4 \mathrm{amu}$ for the $\mathrm{C} 12$ isomer $)$ with the first peak $(\mathrm{m} / \mathrm{z}, 411.4)$ arising from protonation in 111 the ion source and the second $(\mathrm{m} / \mathrm{z}$ 428.4) due to addition of ammonium arising from trace 112 ammonia in the lab air. Control experiments with pure squalene confirm this assignment (Figure $113 \mathrm{~S} 1$ ). Second, we attribute the strong peak at $m / z, 369.3$ to skin lipid sterols, such as cholesterol and 114 lathosterol. ${ }^{25}$ Control experiments (Figure S2) demonstrate that cholesterol is detected at $\mathrm{m} / z .369 .3$ 115 following loss of water from protonated cholesterol $(\mathrm{m} / \mathrm{z}, 387.3)$, a common fragmentation for 116 protonated alcohols. This peak in the skin oil may also arise from sterol esters. ${ }^{29}$ Third, there is a 117 cluster of peaks from just below $m / z 800$ to 1000 (see Table S1). These peaks likely arise from 118 triglycerides, with roughly equal abundance in skin lipids of the unsaturated and saturated forms. ${ }^{25}$ 119 The unsaturated forms have hydrocarbon chains 14-24 carbon atoms long (i.e. MW=700-1100 120 amu). Results from a control experiment with a pure C18 mono-unsaturated triglyceride, triolein 121 (MW = 884.8 amu for C12 isomer), are shown in Figure S3. The DART-MS spectrum shows 122 intensity for ammoniated triolein $(\mathrm{m} / \mathrm{z}, 902.7)$ and a fragment ion of protonated triolein $(\mathrm{m} / \mathrm{z}, 603.5)$ 123 following the loss of a C18 mono-unsaturated fatty acid ( $\mathrm{MW}=282.4 \mathrm{amu})$. The fourth cluster of 124 peaks in the positive ion mass spectrum, i.e. those between $\mathrm{m} / \mathrm{z} 450$ and 600 (Table S1), may arise 125 from the triglycerides or waxy esters (typically mono- and di-esters with 10 to 20 carbon chains,

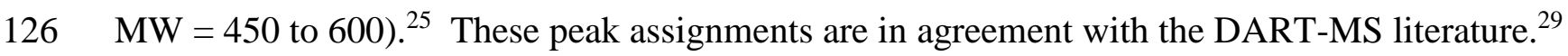

128 A fifth important class of compounds, the long-chain fatty acids, is observed with three large peaks 129 in the negative ion spectrum at $\mathrm{m} / \mathrm{z}, 253.2,255.2$ and 281.2 (Figure $1 \mathrm{~b}$ and Table S1). These likely 
correspond to the most abundant fatty acids in skin lipids, cis-hexadec-6-enoic acid (MW=254.2 amu for C12 isomer), palmitic acid (MW=256.2 amu for C12 isomer), and cis-octadec-8-enoic acid (MW=282.3 amu for $\mathrm{C} 12$ isomer) ${ }^{25}$ Organic acids are detected by proton abstraction in negative ion mode DART-MS, i.e. at $\left[\mathrm{M}-\mathrm{H}^{+}\right]^{-}$.

The most prominent peak in the negative ion spectrum is observed at $m / z$ 128.0. Control experiments show that glutamic acid and pyroglutamic acid contribute to this mass (Figure S4). Using HPLC-MS analysis (see SI-Text, Figures S5, S6), we established that this peak is mainly due to pyroglutamic acid, a natural moisturizing substance present at the $1 \%$ level in the human epidermis. ${ }^{21,23,26}$

\section{Oxidation kinetics of skin oil and common skin oil materials}

The blue traces in Figure 1a and 1b correspond to an ozone exposure of $50 \mathrm{ppb}$ for 90 minutes. There is loss of intensity in a large number of peaks and formation of intensity at others. The squalene peaks lose their prominence entirely, the triglyceride peaks are significantly depleted, as are peaks from $m / z, 450$ to 600 (see Table S1). The intensity of the sterol peak at $m / z, 369.3$ is reduced slightly but decreases by $50 \%$ when exposed to 300 ppb ozone for 45 minutes (data not shown). In the negative ion mode, the peaks due to the fatty acids all decrease substantially with the peak at $\mathrm{m} / \mathrm{z} 255.2$ (likely palmitic acid) decreasing to $\sim 60 \%$ of its starting value and those at $\mathrm{m} / \mathrm{z} 253.2$ and 281.2 decreasing more than $70 \%$.

Squalene is an unsaturated compound that reacts rapidly with ozone. ${ }^{16-18}$ A decay plot demonstrates the rapid kinetics of pure squalene heterogeneous ozonolysis, with an e-folding lifetime of 10 minutes with $50 \mathrm{ppb}$ ozone (Figure 2c). Triolein, the oleic acid tri-ester of glycerol, shows similar reactivity (Figure 2d). These liquids react more rapidly than pure cholesterol which is a solid at ambient temperature (Figure 2b). Although cholesterol is known to react with ozone ${ }^{30,31}$ its phase may be the reason for the lower reactivity.

The sterol peak $(m / z$ 369.3) shows similar loss kinetics to that of pure cholesterol (Figure $2 \mathrm{~b})$, with a small decay at early times. By comparison, the peaks due to squalene $(\mathrm{m} / \mathrm{z} 411.4)$ and cishexadec-6-enoic acid $(\mathrm{m} / \mathrm{z}, 253.2)$ show more reactivity, with some saturation of the reactivity at 
161 long times (Figure 2d). This is likely due to burial of some of the molecules in the skin oil matrix,

162 limiting exposure to ozone at the surface. For probably the same reason, the squalene signal does

163 not decay as rapidly as when present as a pure compound, with an e-fold lifetime of about 30

164 minutes (Figure 2c). The peak assigned to palmitic acid ( $\mathrm{m} / \mathrm{z} 255.2)$ also exhibits initial decay and

165 the same plateau in the signal at long times (Figure 2d). Since palmitic acid does not react directly

166 with ozone, this may be due to reaction with reactive intermediates such as Criegee biradicals.

167 Whether other species also react with intermediates of this type is not known.

169 The peak due to pyroglutamic acid does not decay with ozone (Figure 2a) consistent with it not 170 containing a carbon-carbon double bond. This chemical may be a convenient tracer of human skin 171 oil contamination in indoor environments, given its relatively high abundance and low reactivity 172 with ozone.

1743 . Products formed from oxidation of skin oil and common skin oil materials

175 The pure substance experiments help to interpret the oxidation products. Prominent products from 176 squalene are observed only in the negative ion mode. The dominant peaks at $\mathrm{m} / \mathrm{z} 115.0$ and 117.0 177 are consistent with levulinate and succinate anions, respectively (Figure S1). The corresponding 178 acids are reaction end products, formed via successive ozonolysis reactions at the multiple carbon179 carbon double bonds in squalene, yielding at each step carbonyl and carboxylic acid functional 180 groups upon bond breakage. These products are present in the skin oil oxidation experiment, as 181 seen in the inset in Figure 1b. Other dicarboxylic acids, including adipic acid and suberic acid, 182 arising from oxidation of the most common unsaturated acids, cis-hexadec-6-enoic acid and cis183 octadec-8-enoic acid, respectively, are also observed at $m / z 145.0$ and 173.1. We note that a study 184 of squalene oxidation indicated substantial product formation at high molecular weights. ${ }^{19}$ The 185 positive ion DART-MS spectra of squalene similarly show the formation of high MW products 186 upon ozone oxidation (>450 amu) (Figure S1).

188 Although cholesterol reacts slowly, the products formed $(\mathrm{m} / \mathrm{z} 385.3,401.3,417.3$ in the positive 189 ion spectrum and $\mathrm{m} / \mathrm{z} 433.3$ in the negative ion spectrum, Figure S2) arise from addition of 1, 2 or 1903 oxygen atoms, respectively, to its carbon-carbon double bond. For example, the three-oxygen 191 product, i.e. $\mathrm{m} / \mathrm{z} 417.3$ in the positive ion spectrum, could arise from ozonolysis of the carbon- 
192 carbon double bond into an aldehyde and carboxylic acid. Given the small decay of cholesterol, it

193 is not possible to identify these product peaks in the skin oil spectrum.

195 The positive ion DART-MS spectra of triolein before and after exposure are shown in Figure S3.

196 It is not surprising that, with three double bonds, triolein yields a large number of ozonolysis 197 products that are observed from $m / z$ 450-800. A common feature is that they all have molecular 198 weights lower than the parent triolein molecule, indicating that ozonolysis leads to cleavage of an 199 alkyl chain and formation of a distribution of smaller products. These observations are consistent 200 with those made from the skin oil experiments in which high MW skin oil components $(\mathrm{m} / \mathrm{z} 750$ 201 to 1000) disappeared after ozone reaction whereas lower MW species from $\mathrm{m} / \mathrm{z} 450-800$ formed. 202 The most intense peak in the negative ion mass spectrum $(\mathrm{m} / \mathrm{z}, 157.1)$ is consistent with the 203 formation of nonanoic acid, a low volatility product arising from ozonolysis of the oleate chain in 204 triolein.

206 To illustrate the kinetics of product formation, the time-dependent signals of oxidation products 207 from squalene and cis-hexadec-6-enoic acid are shown in Figure 2c,d, along with a likely oxidation 208 product at $m / z(-) 585.3$ from unsaturated triglycerides. This oxidation product was observed from 209 triolein (Figure S3).

\section{4. Environmental Significance}

212 This investigation is the first mass spectrometry study of the chemical changes occurring in the 213 condensed phase when skin oil is exposed to ozone. By focussing on the condensed phase products, 214 this work complements earlier studies that addressed the gas-phase products formed when ozone 215 interacts with human lipid materials containing species such as squalene. ${ }^{4}$

217 Driven by the unsaturated skin oil components present, the oxidative transformation is rapid as 218 seen by the significant change observed in the DART-MS spectrum after 90 minutes exposure to $21950 \mathrm{ppb}$ ozone. Specifically, squalene and the unsaturated fatty acids in skin oil have an oxidation 220 timescale on the order of tens of minutes at this ozone mixing ratio, a common outdoor value 221 during smog episodes; this lifetime will be longer indoors which typically have ozone levels 0.2 222 to 0.8 of those outdoors. ${ }^{32}$ We note that given the amount of time spent indoors, human ozone 
223 exposure is frequently dominated by indoor exposure. ${ }^{32}$ The values used here, i.e. 75 ppb hours, 224 are environmentally relevant being equivalent to one hour outdoors at 75 ppb ozone or 7.5 hours 225 indoors at $10 \mathrm{ppb}$. There is evidence for the formation of a suite of highly oxygenated species, 226 composed of carboxylic acids such as succinic acid, levulinic acid, higher dicarboxylic acids, and 227 highly functionalized species. One species, pyroglutamic acid, is not reactive with ozone which 228 may make it useful as a tracer of human contamination indoors.

230 These results imply that the oils covering human skin and those deposited to indoor surfaces are 231 being continually oxidized under ambient conditions, with a mixture of both endogenous 232 components alongside their heterogeneous oxidation products. The oxidation products are less 233 reactive than the precursors, thus making the surfaces less reactive than a fresh skin oil surface. 234 As well, the impacts of the observed loss kinetics of the many skin oil species could be related to 235 ozone loss indoors, using a coupled indoor air - multiphase chemistry model. It will be important 236 to determine the toxicological properties of the oxidation products given earlier work that has 237 indicated that squalene oxidation gives rise to redox-active condensed-phase materials and gas238 phase products that are irritants. ${ }^{18,33}$

\section{Supporting Information:}

241 Mass spectra (with and without ozone) of squalene, cholesterol, triolein and their ozonolysis 242 products obtained by DART-MS (Figure S1-S3); mass spectra of glutamic and pyroglutamic acids 243 obtained by DART-MS (Figure S4) and ESI-MS (Figure S5); extracted ion chromatograms of

244 HPLC-MS analysis of glutamic and pyroglutamic acids (Figure S6); lists of major peaks of skin 245 oil, squalene, cholesterol and triolein and their ozonolysis products (Table S1-S4); description of 246 the HPLC-MS analysis (SI-Text).

\section{Acknowledgements}

249 This work was supported by the Sloan Foundation, Grant G2013-10-05.

\section{References}

(1) Weschler, C. J., Roles of the Human Occupant in Indoor Chemistry, Indoor Air 2016, 26, 6-24. 
(2) Clark, R. P.; Shirley, S. G., Identification of Skin in Airborne Particulate Matter, Nature 1973, 246, 39-40.

(3) Pandrangi, L. S.; Morrison, G. C., Ozone Interactions with Human Hair: Ozone Uptake Rates and Product Formation Atmos. Environ. 2008, 42, 5079-5089.

(4) Wisthaler, A.; Weschler, C. J., Reactions of Ozone with Human Skin Lipids: Sources of Carbonyls, Dicarbonyls, and Hydroxycarbonyls in Indoor Air, Proc. Natl. Acad. Sci. USA 2009, 107, 6568-6575.

(5) Wisthaler, A.; Tamas, G.; Wyon, D. P.; Strom-Tejsen, P.; Space, D.; Beauchamp, J.; Hansel, A.; Mark, T. D.; Weschler, C. J., Products of Ozone-initiated Chemistry in a Simulated Aircraft Environment, Environ. Sci. Technol. 2005, 39, 4823-4832.

(6) Coleman, B. K.; Destaillats, H.; Hodgson, A. T.; Nazaroff, W. W., Ozone Consumption and Volatile Byproduct Formation from Surface Reactions with Aircraft Cabin Materials and Clothing Fabrics, Atmos. Environ. 2008, 42, 642-654.

(7) Fischer, A.; Ljungstrom, E.; Langer, S., Ozone Removal by Occupants in a Classroom, Atmos. Environ. 2013, 81, 11-17.

(8) Tamas, G.; Weschler, C. J.; Bako-Biro, Z.; Wyon, D. P.; Strom-Tejsen, P., Factors Affecting Ozone Removal Rates in a Simulated Aircraft Cabin Environment, Atmos. Environ. 2006, 40, 6122-6133.

(9) Rim, D.; Novoselec, A.; Morrison, G., The Influence of Chemical Interactions at the Human Surface on Breathing Zone Levels of Reactants and Products, Indoor Air 2009, 19, 324-334.

(10) Rai, A. C.; Guo, B.; Lin, C. H.; Zhang, J. S.; Pei, J. J.; Chen, Q. Y., Ozone Reaction with Clothing and Its Initiated Particle Generation in an Environmental Chamber, Atmos. Environ. 2013, 77, 885-892.

(11) Fadeyi, M. O.; Weschler, C. J.; Tham, K. W.; Wu, W. Y.; Sultan, Z. M., Impact of Human Presence on Secondary Organic Aerosols Derived from Ozone-Initiated Chemistry in a Simulated Office Environment, Environ. Sci. Technol. 2013, 47, 3933-3941.

(12) Weschler, C. J.; Wisthaler, A.; Cowlin, S.; Tamas, G.; Strom-Tejsen, P.; Hodgson, A. T.; Destaillats, H.; Herrington, J.; Zhang, J. J.; Nazaroff, W. W., Ozone-initiated Chemistry in an Occupied Simulated Aircraft Cabin, Environ. Sci. Technol. 2007, 41, 6177-6184.

(13) Kolb, C. E.; Cox, R. A.; Abbatt, J. P. D.; Ammann, M.; Davis, E. J.; Donaldson, D. J.; Garrett, B. C.; George, C.; Griffiths, P. T.; Hanson, D. R.; Kulmala, M.; McFiggans, G.; Poschl, U.; Riipinen, I.; Rossi, M. J.; Rudich, Y.; Wagner, P. E.; Winkler, P. M.; Worsnop, D. R.; O' Dowd, C. D., An Overview of Current Issues in the Uptake of Atmospheric Trace Gases by Aerosols and Clouds, Atmos. Chem. Phys. 2010, 10, 10561-10605.

(14) Abbatt, J. P. D.; Lee, A. K. Y.; Thornton, J. A. Quantifying Trace Gas Uptake to Tropospheric Aerosol: Recent Advances and Remaining Challenges, Chem. Soc. Rev. 2012, 41, $6555-6581$.

(15) Fruekilde, P.; Hjorth, J.; Jensen, N. R.; Kotzias, D.; Larsen, B., Ozonolysis at Vegetation Surfaces: A Source of Acetone, 4-oxopentanal, 6-methyl-5-hepten-2-one, and Geranyl Acetone in the Troposphere, Atmos. Environ. 1998, 32, 1893-1902.

(16) Wells, J. R.; Morrison, G. C.; Coleman, B. K. Kinetics and Reaction Products of Ozone and Surface-bound Squalene, J. ASTM Int. 2008, 5, 1-12.

(17) Petrick, L.; Dubowski, Y., Heterogeneous Oxidation of Squalene Film by Ozone Under Various Indoor Conditions, Indoor Air 2009, 19, 381-391. 
(18) Fu, D.; Leng, C. B.; Kelley, J.; Zeng, G.; Zhang, Y. H.; Liu, Y., ATR-IR Study of Ozone Initiated Heterogeneous Oxidation of Squalene in an Indoor Environment, Environ. Sci. 301 Technol. 2013, 47, 10611-10618.

(19) Fooshee, D. R.; Aiona, P. K.; Laskin, A.; Laskin, J.; Nizkorodov, S. A.; Baldi, P. F., Atmospheric Oxidation of Squalene: Molecular Study Using COBRA Modeling and HighResolution Mass Spectrometry, Environ. Sci. Technol. 2015, 49, 13304-13313.

(20) Park, F. K. C.; Obendorf, S. K., Chemical Changes in Unsaturated Oils upon Aging and Subsequent Effects on Fabric Yellowing and Soil Removal, J. Am. Oil Chem. Soc. 1994, 71, 17-30.

(21) Laden, K.; Sptizer, R., Identification of a Natural Moisturizing Agent in Skin, $J$. Soc. Cosmet. Chem. 1967, 18, 351-360.

(22) Pochi, P. E.; Downing, D. T.; Strauss, J. S., Sebaceous Gland Response in Man to Prolonged Total Caloric Deprivation, J. Invest. Dermatol. 1970, 55, 303-318.

(23) Marstein, S.; Jellum, E.; Eldjarn, L., The Concentration of Pyroglutamic Acid (2pyrrolidone-5-carboxylic Acid) in Normal and Psoriatic Epidermis, Determined on a Microgram Scale by Gas-Chromatography, Clin. Chim. Acta 1973, 49, 389-395.

(24) Downing, D. T.; Strauss, J. S., Synthesis and Composition of Surface Lipids of Human Skin, J. Invest. Dermat. 1974, 62, 228-244.

19-26.

(25) Nicolaides, N., Skin Lipids - Their Biochemical Uniqueness, Science 1974, 186,

(26) Rawlings, A. V.; Scott, I. R.; Harding, C. R.; Bowser, P. A., Stratum-corneum Moisturization at the Molecular-level, J. Invest. Dermat. 1994, 103, 731-740.

(27) Cody, R. B.; Laramee, J. A.; Durst, H. D., Versatile New Ion Source for the Analysis of Materials in Open Air Under Ambient Conditions, Anal. Chem. 2005, 77, 2297-2302.

(28) Zhou, S. M.; Forbes, M. W.; Abbatt, J. P. D., Application of Direct Analysis in Real Time-Mass Spectrometry (DART-MS) to the Study of Gas-Surface Heterogeneous Reactions: Focus on Ozone and PAHs, Anal. Chem. 2015, 87, 4733-4740.

(29) Mess, A.; Enthaler, B.; Fischer, M.; Rapp, C.; Pruns, J. K.; Vietzke, J. P., A Novel Sampling Method for Identification of Endogenous Skin Surface Compounds by Use of DARTMS and MALDI-MS, Talanta 2013, 103, 398-402.

(30) Gumulka, J.; Smith, L. L., Ozonation of Cholesterol, J. Am. Chem. Soc. 1983, 105, 1972-1979.

(31) Dreyfus, M. A.; Tolocka, M. P.; Dodds, S. M.; Dykins, J.; Johnston, M. V., Cholesterol Ozonolysis: Kinetics, Mechanism, and Oligomer Products, J. Phys. Chem. A 2005, $109,6242-6248$.

(32) Weschler, C. J.; Shields, H. C.; Naik, D. V., Indoor Air Exposures, I. Air Waste Manag. Assoc. 1989, 39, 1562-1568.

(33) Anderson, S. E.; Franko, J.; Jackson, L. G.; Wells, J. R.; Ham, J. E.; Meade, B. J., Irritancy and Allergic Responses Induced by Exposure to the Indoor Air Chemical 4-Oxopentanal, Toxicol. Sci. 2012, 127, 371-381. 


\title{
Supporting Information
}

\section{Rapid Oxidation of Skin Oil by Ozone}

\author{
Shouming Zhou*, Matthew W. Forbes, Yasmine Katrib, Jonathan P.D. Abbatt \\ Department of Chemistry, University of Toronto \\ 80 St. George St. \\ Toronto, ON, M5S 3H6, Canada \\ * - to whom correspondence should be addressed (Tel. +1-416-946-7359; Fax. +1-416-946- \\ 7359; email: szhou@chem.utoronto.ca)
}

\section{Summary (9 pages; 6 figures; 4 tables)}

This supporting information contains: Mass spectra (with and without ozone) of squalene, cholesterol, triolein and their ozonolysis products obtained by DART-MS (Figure S1-S3); mass spectra of glutamic and pyroglutamic acids obtained by DART-MS (Figure S4) and ESI-MS (Figure S5); extracted ion chromatograms of HPLC-MS analysis of glutamic and pyroglutamic acids (Figure S6); lists of major peaks of skin oil, squalene, cholesterol and triolein and their ozonolysis products (Table S1-S4); description of the HPLC-MS analysis (SI-Text). 

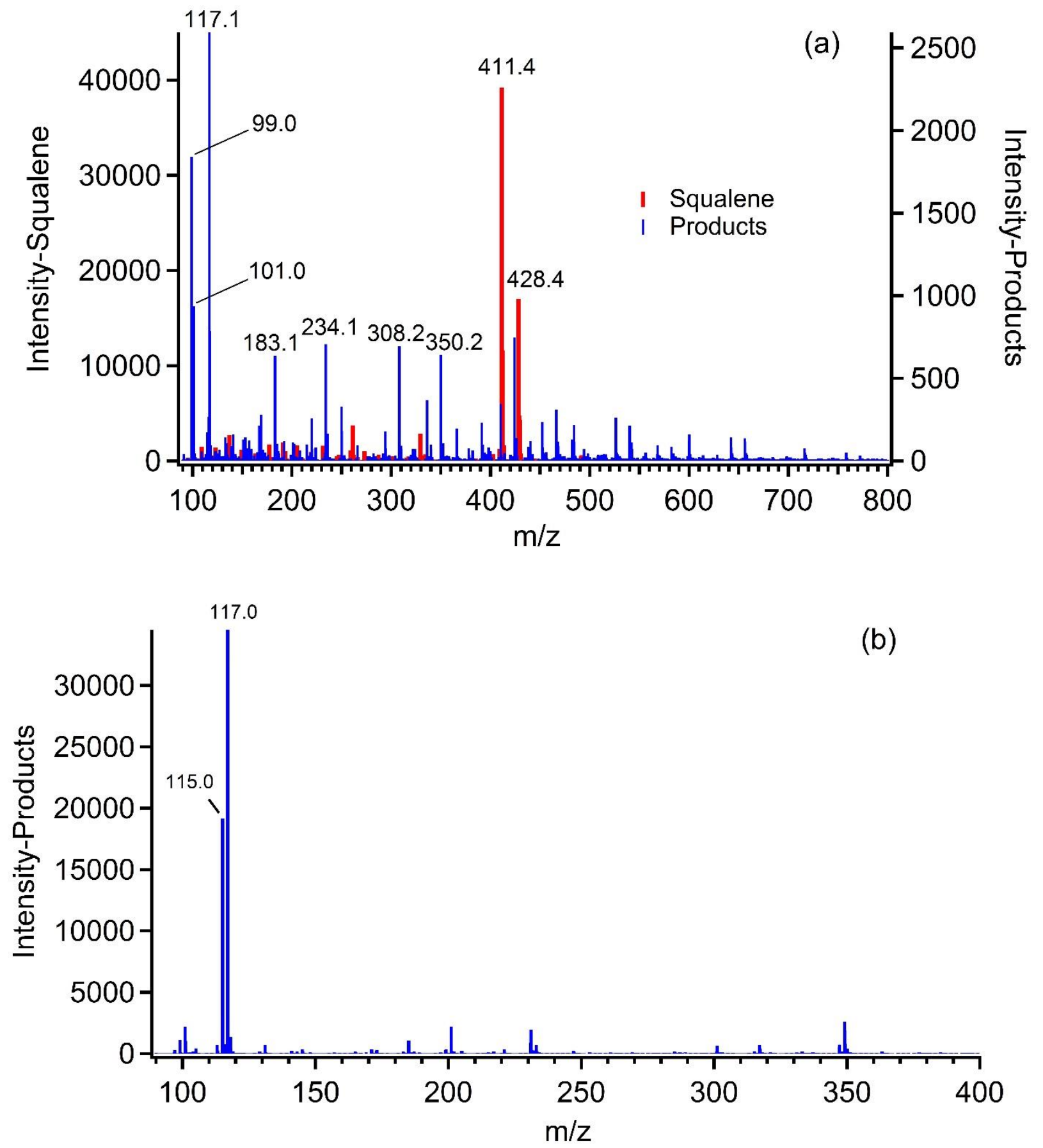

Figure S1. Mass spectrum (red) of squalene obtained under positive (a) and negative (b) modes. The blue trace is the product difference mass spectrum, i.e. it is the mass spectrum formed by subtracting that observed of pure squalene from that observed after squalene is exposed to ozone at $50 \mathrm{ppb}$ for 90 minutes. Note the different scales on the y-axes in (a). 

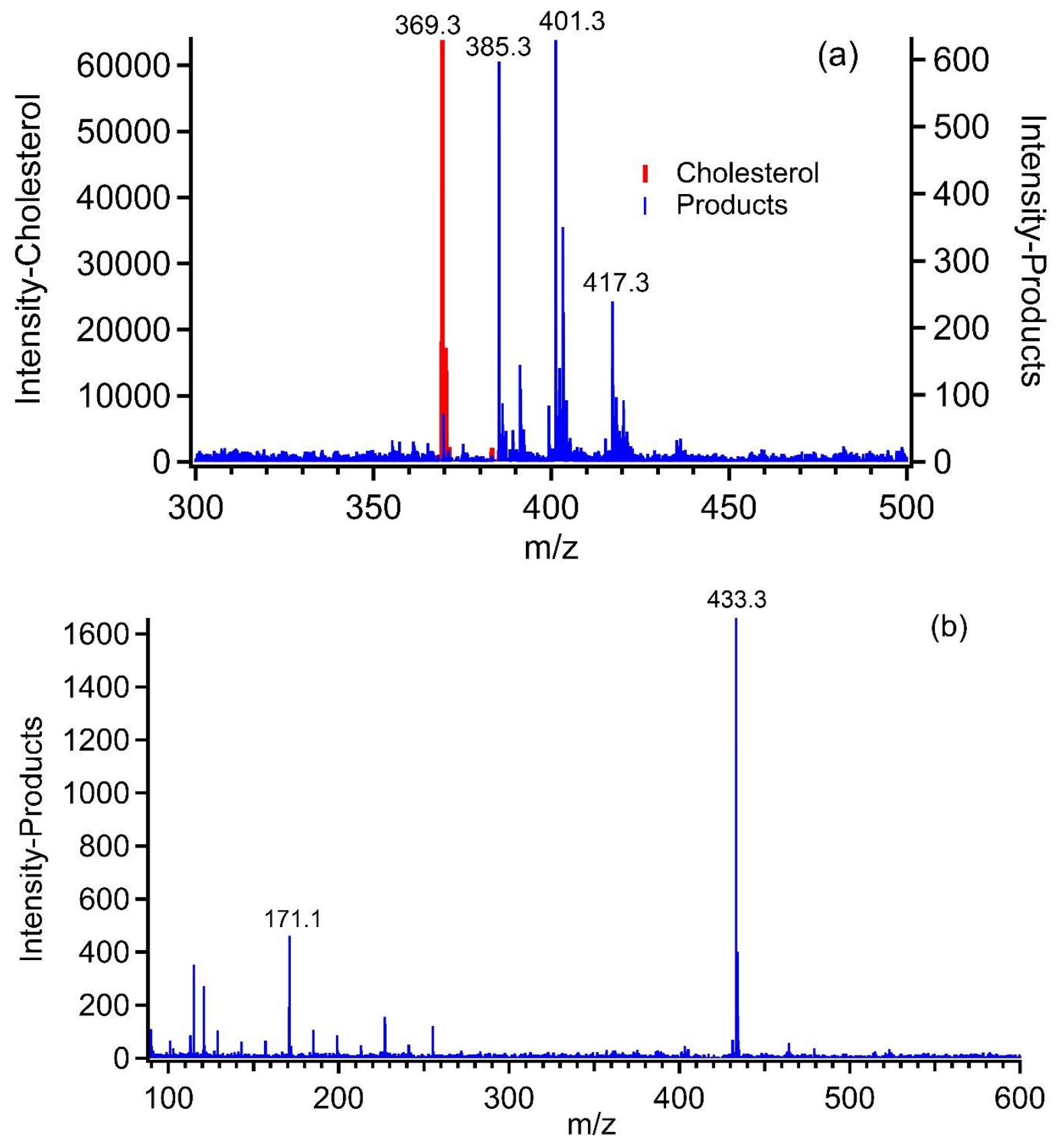

Figure S2. Mass spectrum (red) of cholesterol obtained under positive (a) and negative (b) modes. The blue trace is the product difference mass spectrum, i.e. it is the mass spectrum formed by subtracting that observed of pure cholesterol from that observed after squalene is exposed to ozone at $50 \mathrm{ppb}$ for 90 minutes. Note the different scales on the y-axes in (a). 

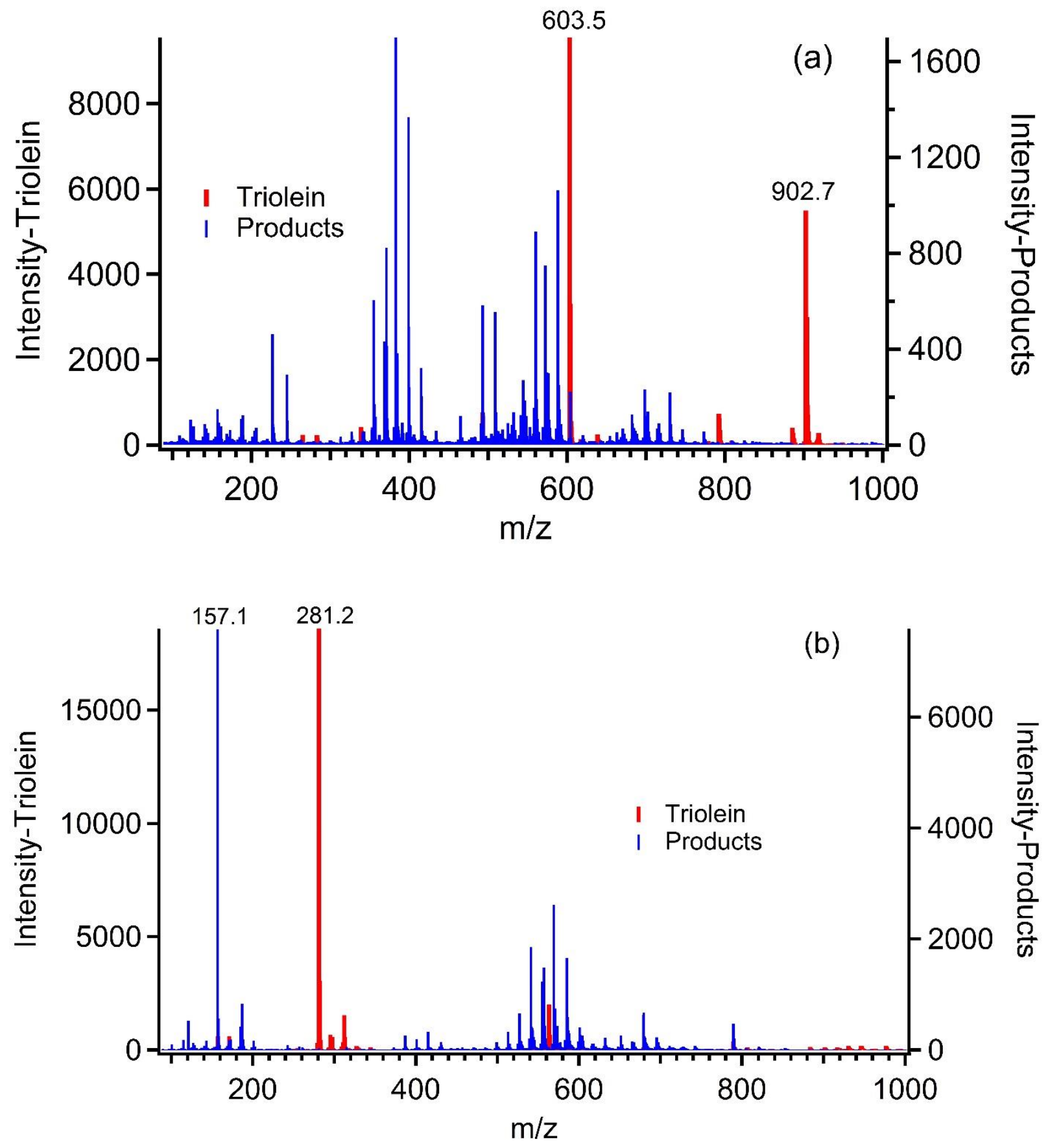

Figure S3. Mass spectrum (red) of triolein obtained under positive (a) and negative (b) modes. The blue trace is the product difference mass spectrum, i.e. it is the mass spectrum formed by subtracting that observed of pure triolein from that observed after squalene is exposed to ozone at $50 \mathrm{ppb}$ for 90 minutes. Note the different scales on the y-axes in (a). 

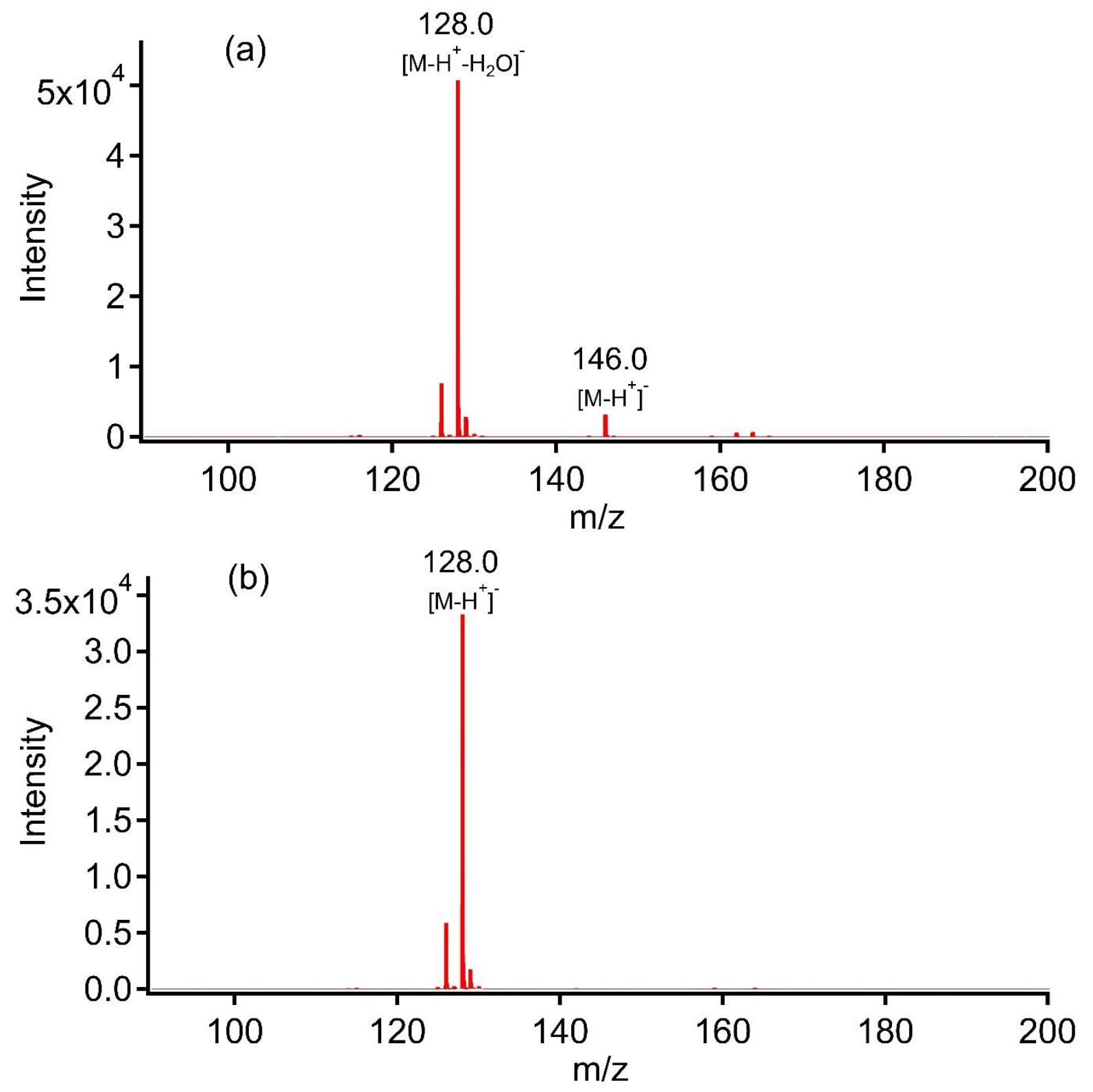

Figure S4. Mass spectrum of glutamic (a) and pyroglutamic acid (b) measured by DART-MS under negative mode. For glutamic acid $m / z, 146$ and 128 (a) are due to $\left[\mathrm{M}-\mathrm{H}^{+}\right]^{-}$and $\left[\mathrm{M}-\mathrm{H}^{+}-\mathrm{H}_{2} \mathrm{O}\right]^{-}$ , respectively; for pyroglutamic acid (b) $m / z, 128$ is due to $\left[\mathrm{M}-\mathrm{H}^{+}\right]^{-}$. 

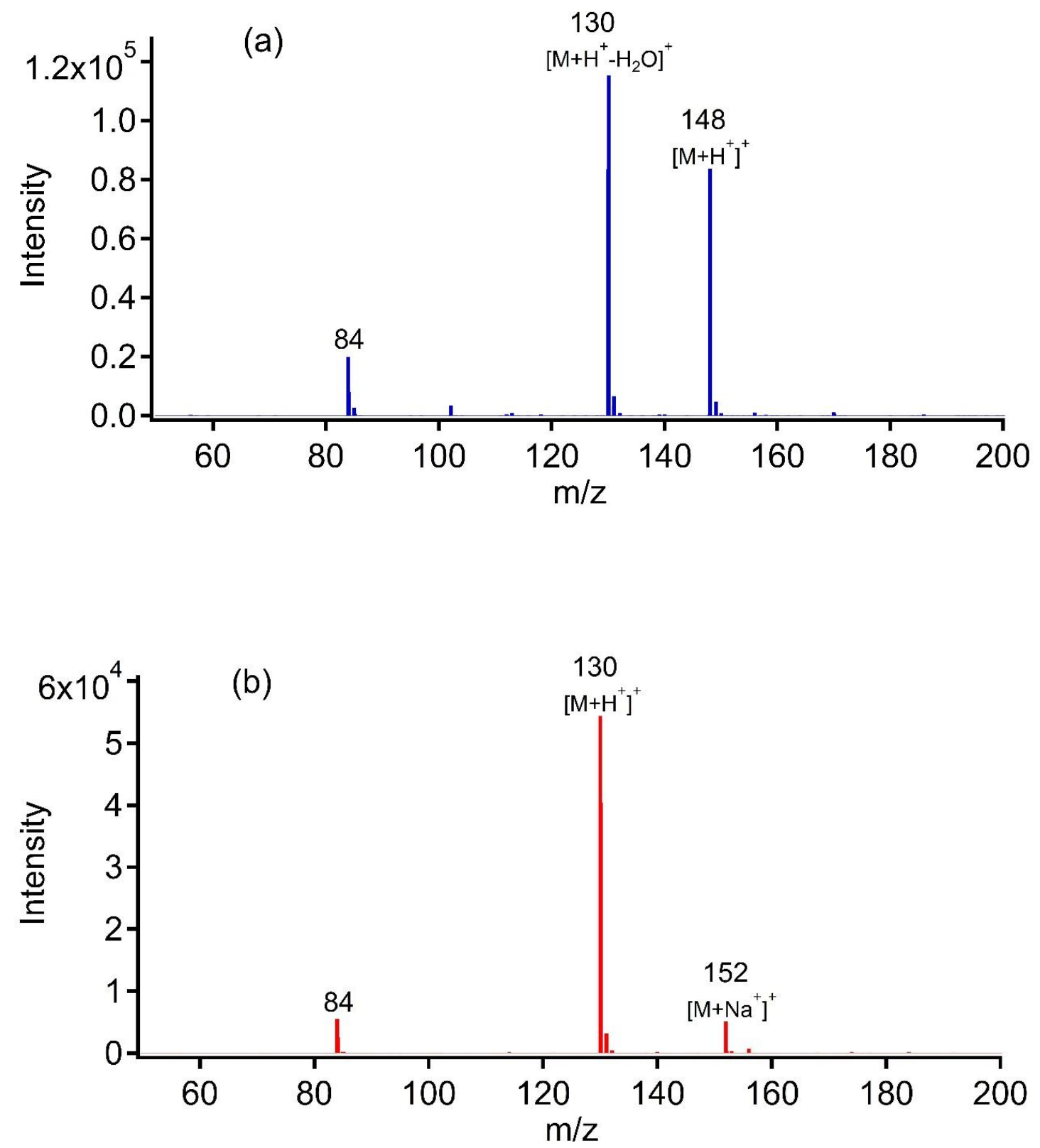

Figure S5. Mass spectra of glutamic acid (a) and pyroglutamic acid (b) obtained by the ESI-MS under positive mode. 

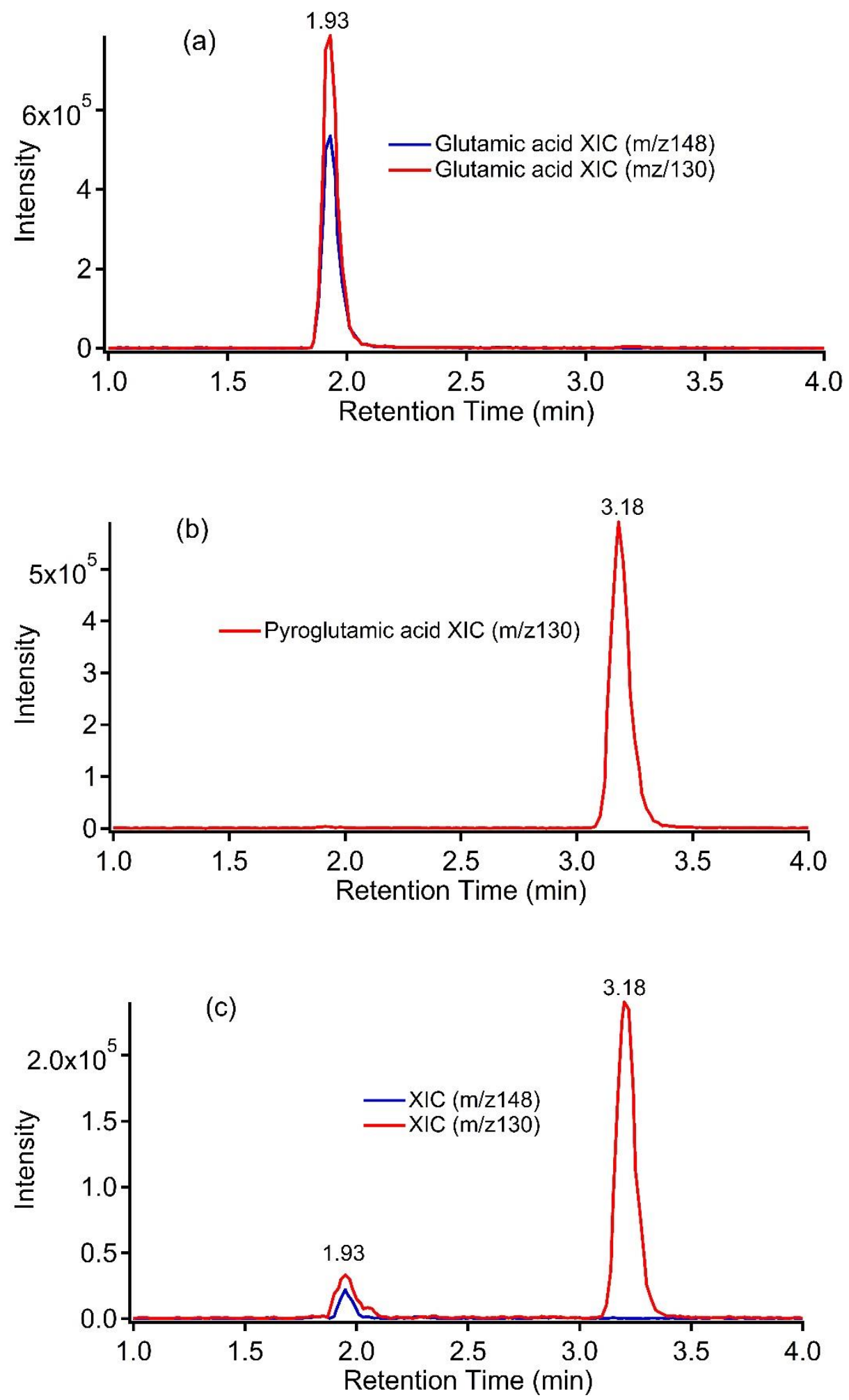

Figure S6. Extracted ion chromatogram (i.e. mass spectral intensity at the indicated mass-tocharge ratio) as a function of retention time) for the HPLC-MS analysis of (a) glutamic acid, (b) pyroglutamic acid and (c) aqueous extract of skin oils (see SI-Text for explanation). 
Table S1. Major peaks of the un-oxidized and oxidized skin oil DART-MS spectra

\begin{tabular}{|l|l|l|}
\hline & \multicolumn{1}{|c|}{ Un-oxidized } & \multicolumn{1}{c|}{ Oxidized } \\
\hline & $130.0,311.1,369.3,411.4,428.4$, & $101.0,117.0,130.0,130.0$, \\
& $451.4,465.4,479.4,493.5,507.5$, & $311.1,369.3,383.3,425.3$, \\
& $521.4,523.4,533.5,535.5,537.4$, & $441.3,453.3,455.3,467.4$, \\
Positive mode & $547.4,549.5,550.5,551.5,563.5$, & $469.3,474.3,523.4,530.4$, \\
& $565.3,575.4,577.5,579.5,806.6$, & $537.4,544.4,551.5,555.8$, \\
& $808.7,820.7,822.7,834.7,836.8$, & $565.5,572.4,586.4,588.4$, \\
& $846.7,848.7$ & $616.4,684.5,686.5,728.5$ \\
\hline \multirow{3}{*}{ Negative mode } & $90.0,137.0,154.1,227.2,253.2$, & $90.0,115.0,117.0,137.0$, \\
& $255.2,281.2,405.0,537.5,798.7$ & $145.0,187.1,255.2,405.0$, \\
& & $457.3,571.4,585.4,599.4$, \\
\hline
\end{tabular}

Table S2. Major peaks of squalene and its ozonolysis products obtained by DART-MS

\begin{tabular}{|l|l|l|}
\hline & Reactants & \multicolumn{1}{|c|}{ Products } \\
\hline Positive mode & $411.4,428.4$ & $99.0,101.0,117.1,183.1,234.1,308.2,350.2$, \\
& & $424.2,452.2,466.3,484.3,526.2,540.3$ \\
\hline Negative mode & None & $101.0,115.0,117.0,201.1,231.1,349.1$ \\
\hline
\end{tabular}

Table S3. Major peaks of cholesterol and its ozonolysis products obtained by DART-MS

\begin{tabular}{|l|l|l|}
\hline & Reactants & \multicolumn{1}{c|}{ Products } \\
\hline Positive mode & 369.3 & $385.3,391.3,401.3,403.3,417.3$ \\
\hline Negative mode & None & $115.0,121.0,171.1,433.3$ \\
\hline
\end{tabular}

Table S4. Major peaks of triolein and its ozonolysis products obtained by DART-MS

\begin{tabular}{|c|c|c|}
\hline & Reactants & Products \\
\hline Positive mode & $603.5,902.7$ & $\begin{array}{l}\text { 227.1, 245.1, 355.2, 371.2, 383.2, 399.2, 415.2, } \\
493.3,509.3,544.3,560.3,572.3,588.3,682.5 \text {, } \\
698.5 .730 .4\end{array}$ \\
\hline Negative mode & $281.2,563.5$ & $\begin{array}{l}\text { 157.1, 187.1, 527.3, 541.3, 557.3, 569.3, 585.3, } \\
679.4,789.6\end{array}$ \\
\hline
\end{tabular}


SI - Text

\section{HPLC-ESI-MS Analysis of Glutamic and Pyroglutamic Acids in Skin Oil:}

Kimwipes were used to collect skin oils from the participant. The Kimwipes were cleaned by sonication with $20 \mathrm{~mL}$ dichloromethane for 15 minutes followed by 15 minutes sonication with $20 \mathrm{~mL}$ methanol and then drying under nitrogen. The skin oils were collected by wiping the participant's face and arms with the Kimwipes that were then extracted by sonication with $20 \mathrm{~mL}$ Milli-Q water. The aqueous extract was directly injected into an HPLC-ESI-MS (Agilent 1260 Infinity binary HPLC coupled to Agilent 6538 UHD quadrupole time-of-flight mass spectrometer) for analysis. The standards were prepared by dissolving the glutamic and pyroglutamic acids in Milli-Q water. Blank samples were extracted and analyzed in an analogous manner as the skin oil samples.

Figure S5 shows the mass spectra of glutamic (a) and pyroglutamic acid (b) obtained by ESI-MS in the positive ion mode. Figure S6 shows the extracted ion chromatograms of the HPLC-MS analysis of glutamic acid standard $(\sim 0.1 \mathrm{mM})$ (a), pyroglutamic acid standard ( 0.1mM) (b) and the aqueous extract of the skin oil (c). The HPLC separation was made using a $100 \mathrm{~mm} \times 4.6 \mathrm{~mm}$ Gemeni NX $5 \mu \mathrm{m}$ C18 column (Phenomenex, Torrance, CA) and mobile phase consisting of $0.1 \%$ formic acid in water (A) and acetonitrile (B) at a flow rate of $0.5 \mathrm{~mL} / \mathrm{min}$. The mobile phase gradients were as follows: 0 min 5\% B-1 min 5\% B-11 min 95\% B-11.01 min 95\% B-14 min $100 \% \mathrm{~B}-14.01 \min 5 \% \mathrm{~B}-15 \min 5 \% \mathrm{~B}$. 